\title{
Antipermeability and antiproliferative effects of standard and frozen bevacizumab on choroidal endothelial cells
}

\author{
Swaantje Peters, Sylvie Julien, Peter Heiduschka, Salvatore Grisanti, Focke Ziemssen, Martin Adler, \\ Ulrich Schraermeyer, Karl-Ulrich Bartz-Schmidt, the Tuebingen Bevacizumab Study Group
}

Br J Ophthalmol 2007;91:827-831. doi: 10.1136/bjo.2006.109702

\begin{abstract}
See end of article for authors' affiliations

Correspondence to Dr S Peters, University Eye Hospital, Eberhard-Karls University Tuebingen, Schleichstrasse 12, D-72076 Tuebingen, Germany; swaantje.peters@gmx.de
\end{abstract}

Accepted 11 December 2006 Published Online First 19 December 2006

\begin{abstract}
Background: Bevacizumab is an antiangiogenic compound developed to target tumour vessels. Its off-label use in ophthalmology requires in vitro testing on ocular cells.

Aim: To quantify the antipermeability and antiproliferative effects of bevacizumab on cultured choroidal endothelial cells (CECs). It was examined whether deep-freezing of bevacizumab attenuates its antiangiogenic activity.

Methods: Porcine CECs were cultured in permeable insert systems. Permeability of the cell monolayers was quantified by a fluorescent isothiocyanate-dextran assay after treatment with vascular endothelial growth factor (VEGF; 20-100 ng/ml) alone and in combination with bevacizumab $(0.1-1 \mathrm{mg} / \mathrm{ml}$ ). Proliferation of the CECs was tested using a "wound scratch" assay. The experiments were repeated with bevacizumab after freezing at $-20^{\circ} \mathrm{C}$ for 5 days.

Results: Bevacizumab significantly reduced VEGF-induced permeability in a dose-dependant manner. A molar ratio of 2.6:1 of bevacizumab to VEGF was required for complete blocking of VEGF-induced rise in permeability. CEC proliferation was significantly blocked by bevacizumab $(0.5 \mathrm{mg} / \mathrm{ml})$. Thawed bevacizumab after deep freezing showed a moderate, but not statistically significant loss in activity.

Conclusion: Bevacizumab significantly reduces VEGF-induced permeability and proliferation of CECs. Freezing and thawing of bevacizumab will affect its biological activity.
\end{abstract}

B evacizumab is a genetically engineered humanised monoclonal IgG antibody against vascular endothelial growth factor (VEGF) that was originally developed to target tumour vessels. ${ }^{1}$ VEGF-A-in particular, via its receptor VEGFR-2-is the most important stimulator for the growth of blood vessels in normal and pathological conditions. ${ }^{2}$ Blockade of this growth factor inhibits endothelial cell proliferation, migration and permeability, ${ }^{3}$ leading to a regression of the feeding tumour vessels and subsequently to a regression of the tumour. The drug is approved by the Food and Drug Administration (FDA) for the adjuvant treatment of metastatic colorectal cancer, but not for use in ophthalmology. However, bevacizumab is now often used as an off-label treatment for ocular neovascular diseases such as age-related macular degeneration (ARMD), high myopia or diabetic retinopathy.

Upregulation of VEGF expression, ${ }^{4}$ combined with changes in Bruch's membrane and the retinal pigment epithelium, seem to promote an angiogenic response. Choroidal endothelial cells (CECs) with increased vascular permeability proliferate and migrate towards the retina, thus forming the typical choroidal neovascular membrane $e^{5}$ with the potential of leakage and haemorrhage. This process can now be reduced with VEGFneutralising agents, ${ }^{6}$ such as pegaptanib, ranibizumab and bevacizumab. Recent clinical studies demonstrate that intravitreally applied bevacizumab significantly reduced macular oedema and improved visual acuity in patients with ARMD and high myopia, ${ }^{7-9}$ without any severe safety risks described so far. ${ }^{10}$

Despite these excellent clinical results, no in vitro testing has been done on CECs so far. Hence, the aim of our study was to quantify the antipermeability and antiproliferative effects of bevacizumab on cultured CECs.

As the drug obtained from the pharmacy is not aliquoted for intravitreal use, but comes in larger infusion flasks for intravenous application in patients with tumours, aliquots are often frozen for storage before injection. Therefore, we examined whether there is any loss of biological activity after freezing and thawing bevacizumab.

\section{MATERIALS AND METHODS}

Isolation of porcine CECs

CECs were isolated from porcine eyes according to the method of Hoffmann et al. ${ }^{11}$ Porcine eyes were transported to our laboratory on ice from a local abattoir. After removing the connective tissue from the eyes, they were washed with ethanol for $1 \mathrm{~min}$ and soaked in penicillin/streptomycin (5\%) for $30 \mathrm{~min}$. The eyes were cut circumferentially behind the limbus, and the anterior segment as well as the vitreous were discarded. The retina was removed and the retinal pigment epithelium was gently scraped off the choroid. The choroid was cut into small pieces and incubated with $0.5 \%$ trypsin for $20 \mathrm{~min}$ at room temperature. Washing was followed by a second digestion step with $0.1 \%$ collagenase (Boehringer, Mannheim, Germany), $0.15 \mathrm{mg} / \mathrm{ml}$ tosyl-lysine-chlor-methylketone (Sigma) and type 2 desoxyribonuclease 1 ( $20 \mathrm{U} / \mathrm{ml}$, Sigma, Steinheim, Germany). The cell suspension was washed thrice with Hank's balanced salt solution containing bovine serum albumin, shaking the tube after each washing step. Cells were filtered through a $70 \mu \mathrm{m}$ mesh filter (Millipore, Watford, UK), and the filtrate was centrifuged. After discarding the supernatant, cells were resuspended in endothelial cell basal medium (Cambrex, Wokingham, UK). Then the endothelial cells were separated using CD31 Dynabeads (Dynal, Invitrogen, Paisly, UK), following the supplier's instructions. The isolated CECs were seeded in endothelial cell growth medium for microvascular cells

Abbreviations: $A R M D$, age-related macular degeneration; CEC, choroidal endothelial cell; CFA, cell-free area; FDA, Food and Drug Administration; FITC, fluorescent isothiocyanate; VEGF, vascular endothelial growth factor 


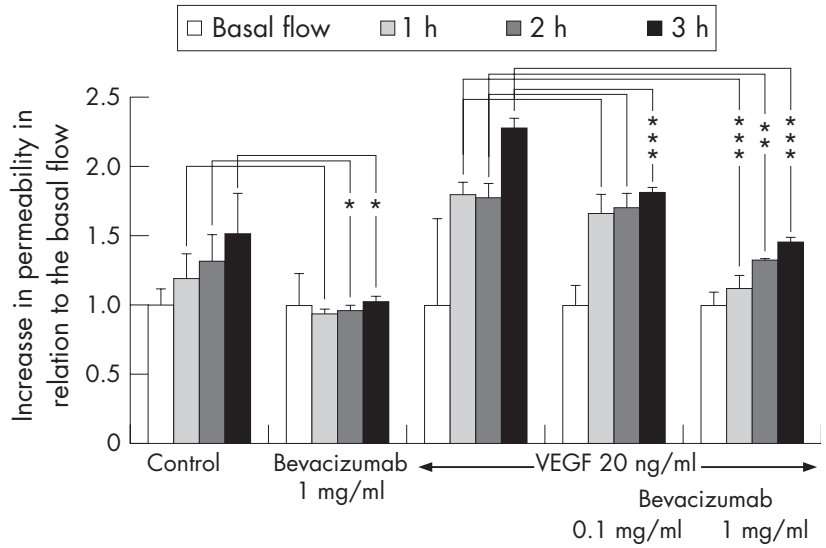

Figure 1 Effects of bevacizumab on vascular endothelial growth factor (VEGF; $20 \mathrm{ng} / \mathrm{ml}$ )-mediated choroidal endothelial cell (CEC) permeability. In a CEC monolayer treated with $20 \mathrm{ng} / \mathrm{ml}$ VEGF, permeability is more than doubled compared with the basal flux in this fluorescent isothiocyanate-dextran assay $(p<0.01$ at $3 \mathrm{~h}$ ). Addition of $0.1 \mathrm{mg} / \mathrm{ml}$ bevacizumab inhibits VEGF-induced permeability significantly $(p<0.001)$. This effect can even be improved by increasing the dose of bevacizumab to $1 \mathrm{mg} / \mathrm{ml}(\mathrm{p}<0.001)$. With $1 \mathrm{mg} / \mathrm{ml}$ of bevacizumab, the permeability of a VEGF-treated CEC monolayer is reduced to the level of untreated monolayers. If just bevacizumab is added to non-stimulated cells, there is no increase in permeability over time. ${ }^{*} p<0.05 ;{ }^{* *} p<0.01 ;{ }^{* * *} p<0.001$. SDs are shown.

(EGM-2MV, Cambrex). The medium was exchanged the day after seeding and then every other day. Isolated endothelial cells were examined microscopically; localisation of the magnetic beads and CD31-immunohistochemical were used to identify the CEC.

\section{Culture in permeable insert systems}

Porcine CECs at passage four were seeded in growth medium (EGM-2MV) onto fibronectin-coated membranes of permeable insert systems (Transwell, Falcon, BD Labware, Bedford, USA, pore size $0.45 \mu \mathrm{m}$, growth area $0.33 \mathrm{~cm}^{2}$ ) with a seeding density of 30000 cells $/ \mathrm{cm}^{2}$. The medium was exchanged the next day, and every other day thereafter. Confluency was usually reached on day 4 .

\section{Dextran permeability assay}

Only confluent monolayers assessed by phase-contrast microscopy were used for the assay. Then cells were incubated with assay medium for $24 \mathrm{~h}$, the medium (EGM-2MV) containing only $1 \%$ fetal calf serum and no growth factors.

Permeability of a confluent cell monolayer was determined by a fluorescence-based assay as reported previously. ${ }^{12}$ Therefore, we used fluorescent isothiocyanate (FITC)-dextran (Sigma) with a molecular weight of $70 \mathrm{kDa}$, which corresponds to a diameter of approximately $6 \mathrm{~nm}$. The small molecule size allows the dextran to permeate in between neighbouring endothelial cells in the absence of tight junctions as well as through endothelial cell fenestrations. ${ }^{13}$ The ability of the dextran to pass from the upper chamber of the permeable insert system into the lower chamber was used to determine the leakage properties of the monolayer. More dextran in the lower chamber indicates higher permeability. This dextran flux was then quantified by means of the fluorescence in the lower chamber.

The FITC-dextran was prepared in a concentration of $20 \mathrm{mg} /$ $\mathrm{ml}$ in endothelial cell basal medium (Cambrex). A volume of $5 \mu \mathrm{l}$ of the dextran solution was added to the upper well of the insert system. After an incubation time of $30 \mathrm{~min}$ at $37^{\circ} \mathrm{C}, 50 \mu \mathrm{l}$ medium was taken from each lower well and transferred to an assay plate (96-well, polystyrene, flat bottom, Corning, Sigma, Steinheim, Germany). Thus, the basal flow of FITC-dextran through the monolayer was determined. A volume of $50 \mu \mathrm{l}$ fresh assay medium was replaced in the lower chamber. The cells were then incubated with 20 or $100 \mathrm{ng} / \mathrm{ml}$ of recombinant human VEGF (R\&D, Wiesbaden, Germany) for $10 \mathrm{~min}$, as it is known that endothelial cell fenestrations occur after $10 \mathrm{~min} .{ }^{13}$ Control wells did not receive any treatment. Standard bevacizumab (Avastin, Roche, Mannheim, Germany) was added to the wells in concentrations of 0.1 or $1 \mathrm{mg} / \mathrm{ml}$, again sparing controls from treatment. Aliquots of bevacizumab were frozen at $-20^{\circ} \mathrm{C}$ for 5 days, then thawed at room temperature and used for the same set-up of experiment. All treatment combinations were repeated as triplicates. Aliquots of $50 \mu \mathrm{l}$ from each lower well were taken after 1,2 and $3 \mathrm{~h}$ and transferred to the assay plate, where samples were diluted $1: 1$ with assay medium. Gradient dilutions of FITC-dextran in plain assay medium served as a standard dilution curve. Fluorescence was measured using a plate fluorimeter (Safire microplate reader, TECAN, Reading, UK) at an excitation/emission of 490/ $520 \mathrm{~nm}$.

Statistical analysis was performed using non-parametric tests (Mann-Whitney $U$ test). If more than two samples were compared, a correction for multiple testing was used (KruskalWallis test). $\mathrm{p}<0.05$ was considered significant.

\section{Proliferation assay}

To examine the antiproliferative effect of bevacizumab and thawed bevacizumab on CECs, a wound scratch assay was used. ${ }^{14}$ Cells were seeded into 24-well plates and grown to confluency in growth medium (EGM-2MV) containing multiple growth factors. Then growth medium was replaced by assay medium, containing only $50 \mathrm{ng} / \mathrm{ml}$ VEGF, a dose that was found to maximally stimulate CEC. ${ }^{12}$ Then the cultures were scratched with a plastic pipette tip to yield cell-free areas (CFAs) of uniform width and treated with bevacizumab $(0.5 \mathrm{mg} / \mathrm{ml})$. To test whether there is any loss of activity induced by freezing the drug, bevacizumab was used as standard and after freezing at $-20^{\circ} \mathrm{C}$ for 5 days. Control wells, containing either pure assay medium ( $1 \%$ serum, no added growth factors) or VEGF-enriched assay medium, were not

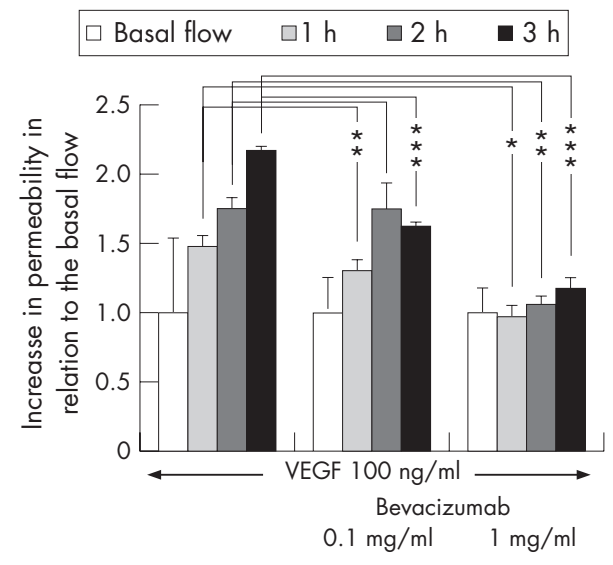

Figure 2 Effects of bevacizumab on vascular endothelial growth factor (VEGF; $100 \mathrm{ng} / \mathrm{ml}$ )-mediated choroidal endothelial cell (CEC) permeability. Permeability of a CEC monolayer treated with $100 \mathrm{ng} / \mathrm{ml}$ VEGF is more than doubled compared with the basal flux in this fluorescent isothiocyanate dextran assay. Addition of $0.1 \mathrm{mg} / \mathrm{ml}$ bevacizumab inhibits VEGF-induced permeability significantly $(p<0.001)$. With $1 \mathrm{mg} / \mathrm{ml}$ bevacizumab, any VEGF-mediated additional permeability over time is completely blocked $(p<0.001)$. The most prominent effects are observed at the $3 \mathrm{~h}$ time point. ${ }^{*} \mathrm{p}<0.05 ;{ }^{* *} \mathrm{p}<0.01 ;{ }^{* * *} \mathrm{p}<0.001$. SDs are shown. 
treated. All assays were done in triplicates. To determine the extent of "wound" closure after $48 \mathrm{~h}$, digital photographs (Zeiss Axiovert 135/AxioCam) were taken (two pictures from each well at randomly chosen areas, magnification $\times 20$ ). The CFA was determined in $\mu^{2}$ by Axiovision 3.1 software. The statistical analysis was performed as described above.

\section{RESULTS}

\section{Dextran permeability assay}

Standard bevacizumab

Previous studies demonstrated that cultured endothelial cells in confluent monolayers preserve their apical-basal polarity. ${ }^{15}$ The fluorescent dextran added to the Transwell inserts permeates through the endothelial cell monolayer into the lower chamber of the system depending on the cellular leakage properties. The fluorescence measured in the lower chamber thus allows quantification of the monolayers' permeability. The basal flow through the endothelial cell monolayers was set at 1 for every sample, and changes in permeability were indicated as relative increase. A moderate rise in permeability was observed in nontreated endothelial cells, which is related to minimal traces of VEGF measured in the assay medium by ELISA (data not shown). Addition of bevacizumab to these untreated cells completely blocked any rise in permeability. In CECs incubated with $20 \mathrm{mg} / \mathrm{ml}$ VEGF, permeability of the monolayers was increased 1.8-fold after $1-2 \mathrm{~h}$ and 2.3-fold after $3 \mathrm{~h}$, compared with the basal flow ( $p<0.01$, fig 1 ). If bevacizumab was added to this set-up at a concentration of $0.1 \mathrm{mg} / \mathrm{ml}$, an increase in permeability was still observed but was less prominent compared with the basal flow, and permeability was increased not more than 1.8 -fold after $3 \mathrm{~h}$. In comparison with the VEGFstimulated monolayers, permeability was significantly reduced by $0.1 \mathrm{mg} / \mathrm{ml}$ bevacizumab $(\mathrm{p}<0.001)$. When increasing the dose of bevacizumab up to $1 \mathrm{mg} / \mathrm{ml}$, permeability remained between 1.1 and 1.45-fold of the basal flow, which is in the range of untreated monolayers. The bevacizumab-related decrease in endothelial cell permeability was highly significant $(\mathrm{p}<0.001)$.

CECs treated with $100 \mathrm{ng} / \mathrm{ml}$ VEGF showed a similar increase in permeability as monolayers treated with $20 \mathrm{ng} / \mathrm{ml}$ (fig 2). This corresponds to the previously observed "hook effect" with no further increasing effect at high doses of VEGF, which was

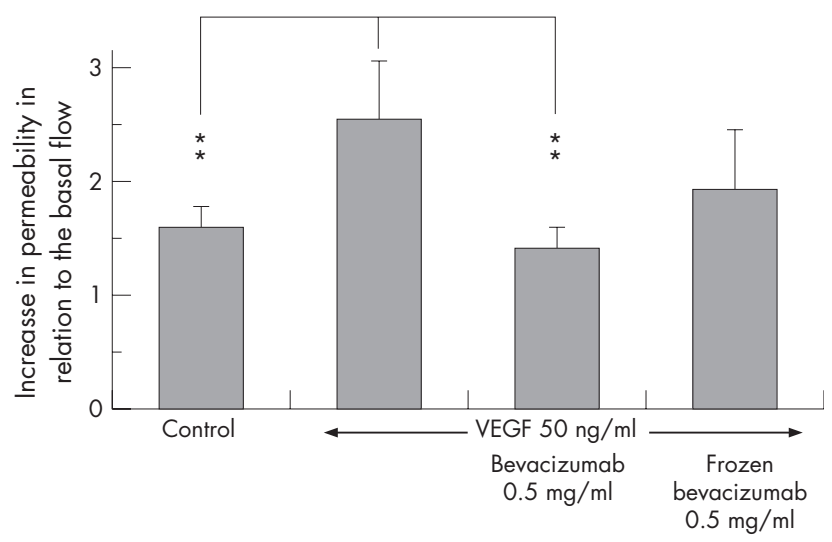

Figure 3 Comparing the antipermeability effect of native and thawed bevacizumab atter freezing at $-20^{\circ} \mathrm{C}$ for 5 days reveals that this procedure leads to a moderate, though not significant, reduction of the antipermeability effect $(p=0.14)$. Vascular endothelial growth factor (VEGF)-induced permeability is not inhibited significantly, as shown for the standard bevacizumab $(p=0.3)$. This should be kept in mind when aliquots of bevacizumab are frozen and thawed before using for the intravitreal injection. Standard bevacizumab leads to a significant reduction in permeability $(p=0.01)$. SDs are shown. supposed to be related to receptor saturation and internalisation. ${ }^{4}$ After $3 \mathrm{~h}$, incubation time permeability was more than doubled compared with the basal flux. Addition of $0.1 \mathrm{mg} / \mathrm{ml}$ bevacizumab in this set-up was able to reduce leakage significantly $(p<0.001)$. Permeability was increased only 1.3-1.6-fold compared with the basal flow. When bevacizumab was added at a concentration of $1 \mathrm{mg} / \mathrm{ml}$, the increase of VEGF-related permeability was minimal and the leakage was also significantly reduced compared with the control $(\mathrm{p}<0.001)$. Permeability of these monolayers remained on the level of the basal flow. The inhibiting effect of bevacizumab on the endothelial cell permeability became increasingly visible with time. Significant reductions in permeability were seen after $1-2 \mathrm{~h}(\mathrm{p}<0.05$ after $\mathrm{l} \mathrm{h}, \mathrm{p}<0.01$ after $2 \mathrm{~h})$, but became more pronounced after $3 \mathrm{~h} \quad(\mathrm{p}<0.001)$. Optimum effects were achieved at a molar ratio of bevacizumab to rhVEGF of $2.6: 1$.

\section{Deep-frozen bevacizumab}

If bevacizumab is frozen at $-20^{\circ} \mathrm{C}$ for 5 days and then thawed, the antipermeability effect is reduced compared with standard bevacizumab without freezing, but this loss of activity was not significant $(p=0.14$; fig 3$)$. In comparison to the standard bevacizumab which causes a significant blockage of VEGFmediated permeability $(p=0.01)$, a significance was not seen for frozen and thawed bevacizumab $(\mathrm{p}=0.3)$.

\section{Proliferation assay}

The extent of the wound closure after $48 \mathrm{~h}$ is a measure of the proliferation of the CECs. If VEGF is abundant, the gap is almost closed at this time point. A large CFA, on the other hand, is consistent with an inhibition of proliferation.

Whereas in the VEGF-stimulated control the CFA after $48 \mathrm{~h}$ incubation time is only $0.18 \mathrm{~mm}^{2}$, the addition of bevacizumab results in a large CFA of $0.46 \mathrm{~mm}^{2}$, indicating a statistically highly significant inhibition of proliferation $(\mathrm{p}<0.005)$. After freezing the drug at $-20^{\circ} \mathrm{C}$, there is a little loss of activity $\left(\mathrm{CFA}=0.41 \mathrm{~mm}^{2}\right)$, but this loss of activity is not statistically significant (fig 4). The frozen and thawed drug still has a significant antiproliferative effect $(\mathrm{p}<0.005)$.

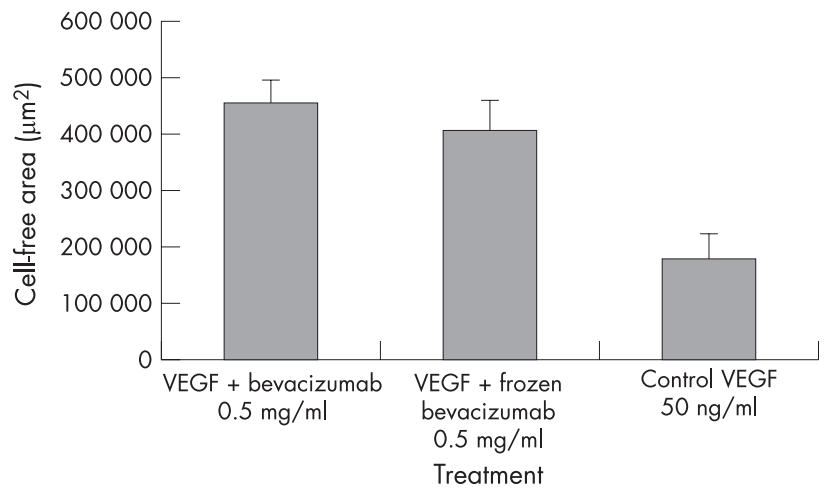

Figure 4 Proliferation assay: bevacizumab $(0.5 \mathrm{mg} / \mathrm{ml})$ significantly inhibits choroidal endothelial cell proliferation. Large cell-free areas (CFAs) indicate strong antiproliferative effects. The CFA in the vascular endothelial growth factor (VEGF)-enriched $(50 \mathrm{ng} / \mathrm{ml})$ control is only $0.18 \mathrm{~mm}^{2}$ ( $p<0.05$ compared with the control); addition of bevacizumab results in a CFA of $0.46 \mathrm{~mm}^{2}$. This CFA is significantly larger compared with the control or with the VEGF-stimulated sample $(p<0.05)$. Deep freezing of bevacizumab leads to a moderate, but not significant, loss of antiproliferative activity (CFA $=0.41 \mathrm{~mm}^{2}, \mathrm{p}=0.34$ ). Compared with the VEGF-enriched sample, there is a significant reduction of endothelial cell proliferation with frozen and thawed bevacizumab $(p<0.05)$. SDs are shown. 

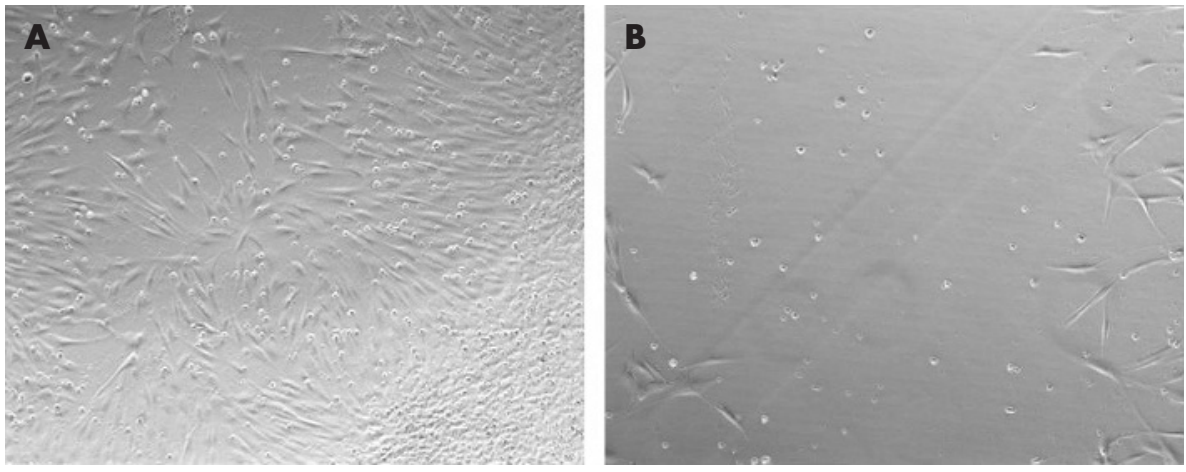

Figure 5 Proliferation assay: if the culture medium contains vascular endothelial growth factor $(50 \mathrm{ng} / \mathrm{ml})$, the gap in this wound scratch assay is almost closed by proliferated endothelial cells after $48 \mathrm{~h}(\mathrm{~A}$, magnification $\times 20)$. If bevacizumab $(0.5 \mathrm{mg} / \mathrm{ml})$ is added to the assay, there is almost no proliferation into the gap, demonstrating the antiproliferative effect of bevacizumab (B).

Even if the cells are kept in assay medium without extra addition of VEGF, a certain amount of proliferation is visible. This is due to traces of VEGF in the $1 \%$ serum-containing medium and parallels the results observed in the dextran permeability assay.

\section{DISCUSSION}

Choroidal neovascularisation with increased vascular permeability has, until recently, been an unresolved problem in patients with exudative ARMD-the most common reason for blindness in older people in the industrial world.

With the knowledge originating from oncology and tumour pathology, clinical studies and experimental work in ophthalmology have been increasingly focused on inhibitors of angiogenic growth factors, ${ }^{16}{ }^{17}$ especially on inhibitors of VEGF, which is the most potent angiogenic factor. VEGF-A is the most abundant member in the VEGF gene family. It can be spliced into several isoforms, and VEGF165 is supposed to be predominantly responsible for pathological neovascularisation in tumours or ARMD, ${ }^{3}$ although other isoforms are involved as well. ${ }^{18}$ Although ophthalmologists may view VEGF as a largely negative factor, especially regarding choroidal neovascular membranes, it also has positive effects: it acts as a survival factor for endothelial cells and as a protector for neuronal cells in the central nervous system and the retina. ${ }^{18}$

Two VEGF inhibitors have been approved by the FDA for ophthalmological use since 2006: pegaptanib (Macugen) and ranibizumab (Lucentis), both showing their effectiveness in large phase III studies (ANCHOR, MARINA, VISION). ${ }^{16} 2021$ Whereas pegaptanib is an aptamer that selectively blocks VEGF165, ranibizumab is a small antibody fragment against all VEGF isoforms. As the antibody fragment ranibizumab has until recently been available only within clinical studies, ophthalmologists started to use the full-length VEGF antibody bevacizumab, which is approved for the adjuvant treatment of metastatic colorectal cancer. In uncontrolled studies, intravitreal bevacizumab led to a significant improvement in visual acuity, reduction in central retinal thickness and improvement in angiographic outcome..$^{922-24}$ To rectify and support the clinical use of an off-label treatment, it is important to obtain in vitro data examining the effectiveness and the safety of this drug.

Our study proves that bevacizumab also exerts its inhibiting effect on CEC permeability and proliferation at the cellular level. Increased VEGF concentrations in choroidal neovascular or exudative disease were simulated by adding rhVEGF to the CECs. Treatment with VEGF more than doubled CEC permeability and proliferation compared with untreated cells. The way in which VEGF mediates leakage is considered to be due to an induction of endothelial cell fenestrations, opening of intercellular junctions, transcellular pathways, nitric oxiderelated pathways or phosphoinositide 3 kinase-protein kinase $\mathrm{B} /$ nitric oxide synthase/mitogen-activated protein-kinase signalling cascades. ${ }^{3} 1425$ Although CECs are not characterised by tight junctions such as retinal endothelial cells, VEGF leads to an increased cellular permeability, as seen in figs 1 and 2. Our experiments demonstrate that bevacizumab is able to completely inhibit this VEGF-related permeability of CECs. A significant reduction in permeability was observed at molar ratios of bevacizumab to rhVEGF above 1.3:1. Best effects, meaning complete blockage of VEGF-related permeability, were demonstrated at a molar ratio of 2.6:1, which corresponds to results obtained from human umbilical vein endothelial cells. ${ }^{12}$

Untreated monolayers also showed a moderate leakage as well as proliferation, which is explained by traces of VEGF in the $1 \%$ serum-containing assay medium. When bevacizumab was added to the untreated endothelial cells, the additional leakage seen over time was completely blocked (fig 1).

This strong antipermeability effect explains the clinically observed resolving of macular oedemas and pigment epithelial detachments after treatment with bevacizumab.

Figures 4 and 5 demonstrate that VEGF-related proliferation of CECs is effectively prevented by bevacizumab $(0.5 \mathrm{mg} / \mathrm{ml})$. Proliferation of treated cells equals proliferation of cells in a growth-factor-deprived medium.

As bevacizumab is approved only to treat colorectal cancer, the drug comes in infusion bottles (100 $\mathrm{mg}$ in $4 \mathrm{ml}$ or $400 \mathrm{mg}$ in $16 \mathrm{ml}$ ) for intravenous use in patients with tumour. For the intravitreal injection, however, small doses of, for example, $1.25 \mathrm{mg}$ in $50 \mu \mathrm{l}$ are required. For this reason, the drug is often aliquoted and frozen for "sterile" short- or long-term storage. However, the results of our study show that short-term freezing already leads to a moderate loss of activity for bevacizumab.

To our knowledge, this is the first study that demonstrates the antipermeability and antiproliferative effects of bevacizumab on cultured CECs. Bevacizumab effectively inhibits VEGFrelated CEC permeability and proliferation, preferentially in a molar ratio to VEGF of 2.6:1. If bevacizumab is frozen and thawed before use, there occurs a moderate loss of antiangiogenic activity compared with that using the native drug.

\section{Authors' affiliations \\ Swaantje Peters, Sylvie Julien, Peter Heiduschka, Salvatore Grisanti, Focke Ziemssen, Martin Adler, Ulrich Schraermeyer, Karl-Ulrich Bartz- Schmidt, University Eye Hospital Tuebingen, Tuebingen, Germany \\ Competing interests: None declared.}




\section{REFERENCES}

1 Marshall J. The role of bevacizumab as first-line therapy for colon cancer. Semin Oncol 2005;32(Suppl 9):S43-7.

2 Ferrara N. VEGF and the quest for tumour angiogenesis factors. Nat Rev Cancer 2002;2:795-803.

3 Hicklin DJ, Ellis LM. Role of vascular endothelial growth factor pathway in tumor growth and angiogenesis. JCO 2005;23:1011-27.

4 Aiello LP, Avery RL, Arrig PG, et al. Vascular endothelial growth factor in ocular fluid of patients with diabetic retinopathy and other retinal disorders. N Engl J Med 1994;331:1480-7.

5 Schlingenmann RO. Role of growth factors and the wound healing response in age-related macular degeneration. Graefe's Arch Clin Exp Ophthalmol 2004;242:91-101.

6 Sakamoto T, Sakamoto H, Murphy TL, et al. Vessel formation by choroidal endothelial cells in vitro is modulated by retinal pigment epithelial cells. Arch Ophthalmol 1995;113:512-20.

7 Avery RL, Pieramici DJ, Rabena MD, et al. Intravitreal bevacizumab (Avastin) for neovascular age-related macular degeneration. Ophthalmology 2006; 113:363-72.

8 Rosenfeld PJ, Moshfeghi AA, Puliafito CA (b). Optical coherence tomography findings after an intravitreal injection of bevacizumab (avastin) for neovascular age-related macular degeneration. Ophthalmic Surg Lasers Imaging 2005; $36: 331-5$

9 Spaide RF, Laud K, Fine HF, et al. Intravitreal bevacizumab treatment of choroidal neovascularization secondary to age-related macular degeneration. Retina 2006;26:383-90.

10 Rich RM, Rosenfeld PJ, Puliafito CA, et al. Short-term safety and efficacy of intravitreal bevacizumab (Avastin) for neovascular age-related macular degeneration. Retina 2006;26:495-511.

11 Hoffmann S, Spee C, Murata T, et al. Rapid isolation of choriocapillary endothelial cells by Lycopersicon esculentum-coated Dynabeads. Graefe's Arch Clin Exp Ophthalmol 1998;236:779-84.

12 Muller WA, Gimbone MA Jr. Plasmalemmal proteins of cultured vascular endothelial cells exhibit apical-basal polarity: analysis by surface-selective iodination. J Cell Biol 1986; 103:2389-402.
13 Wang $Y$, Dei $D$, Vanderlaan $M$, et al. Biological activity of bevacizumab, a humanized anti-VEGF antibody in vitro. Angiogenesis 2004;7:335-45.

14 Roberts WG, Palade GE. Increased microvascular permeability and endothelia cell fenestration induced by vascular endothelial growth factor. J Cell Sci 1995; 108:2369-79.

15 Uitto VJ, Bailie D, Wu Q, et al. Fusobacterium nucleatum increases collagenase 3 production and migration of epithelial cells. Infect Immun 2005;73:1171-9.

16 Gragoudas ES, Adamis AP, Cunningham ET Jr, et al. Pegaptanib for neovascular age-related macular degeneration. N Engl J Med 2004;351:2805-16.

17 Michels S, Rosenfeld PJ, Puliafito CA, et al. Systemic bevacizumab (Avastin) therapy for neovascular age-related macular degeneration twelve-week results of an uncontrolled open-label clinical study. Ophthalmology 2005;112:1035-47.

18 Lee S, Jilani SM, Nikolova GV, et al. Processing of VEGF-A by matrix metalloproteinases regulates bioavailability and vascular patterning in tumors. J Cell Biol 2005; 169:681-91.

19 Robinson GS, JU M, Shih SC, et al. Nonvascular role for VEGF: VEGFR-1,2 activity is critical for neuronal retinal development. FASEB J 2001;15:1215-7.

20 Rosenfeld PJ, Brown DM, Heier JS, et al. Ranibizumab for neovascular agerelated macular degeneration. N Engl J Med 2006;355:1419-31.

21 Brown DM, Kaiser PK, Michels M, et al. Ranibizumab versus verteporfin for neovascular age-related macular degeneration. N Engl J Med 2006;355: 1432-44.

22 Nguyen QD, Shah S, Tatlipinar S, et al. Bevacizumab suppresses choroidal neovascularization caused by pathological myopia. Br J Ophthalmo 2005;89:1368-70

23 Reichel E. Intravitreal bevacizumab for choroidal neovascularization and cystoid macular edema: a cost-effective treatment? Ophthalmic Surg Lasers Imaging 2005;36:270-1.

24 Rosenfeld PJ, Fung AE, Puliafito CA. Optical coherence tomography findings after an intravitreal injection of bevacizumab (avastin) for macular edema from central retinal vein occlusion. Ophthalmic Surg Lasers Imaging 2005;36:336-9.

25 Lal BK, Varma S, Pappas PJ, et al. VEGF increases permeability of the endothelial cell monolayer by activation of PKB/akt, endothelial nitric-oxide synthase, and MAP kinase pathways. Microvasc Res 2001;62:252-62. 